\title{
Design development of a unit operation for chilli paste process
}

\begin{abstract}
The traditional method of chilli paste processes essentially consists of two main unit operations, namely blending of raw ingredients and cooking of liquefied chilli paste, accompanied by manual stirring. The transferring of blended food for cooking adds clean-up work and tends to waste time and energy. Substantive continuous stirring during the cooking process is essential, but time and labour consuming. In this study, a process design of a chilli paste machine has been developed with the aim to combine the process of blending and agitated cooking in a single appliance. A new design of machine called Chilli Paste Machine has been successfully built with the intention to overcome the issues present in making chilli paste. It comprises a set of blades that enable blending or stirring of chilli paste during blending and cooking processes respectively. A heating plate is installed for heating the chilli paste. The whole operation is controlled by a Programmable-Logic-Controller (PLC) Unit which allows automated control of the desired temperature parameters. The prototype machine was tested to ensure the performances of the machine design are met. A ready-toserve batch of chilli paste was successfully produced using this newly designed machine.
\end{abstract}

Keyword: Blending; Chilli paste; Heating; PLC; Stirring 